\title{
Inborn enzymatic defect as the probable cause of the formation of renal stones consisting of uric acid
}

\author{
JERZY KRAWCZYNSKI, ZBIGNIEW SAGAN, ELZBIETA WALAJTYS, AND \\ KRYSTYNA ILOWIECKA
}

\author{
From the Department of Laboratory Diagnostics of the Postgraduate \\ Medical School of Warsaw, Poland
}

SYNOPSIS In four persons of one family the existence of an enzymatic defect, presumably consisting of a deficiency of glutaminase in the cells of the renal tubules, is postulated, and is implied by a reduced elimination of ammonia in the urine, by a relatively low urinary $p \mathbf{H}$, and by its increased titratable acidity. The most characteristic clinical symptom is irritation of the distal part of the urinary tract, connected with numerous crystals of uric acid appearing in the urinary sediment. The elimination of uric acid is normal, or even reduced, and the level of uric acid in the blood serum is also within normal limits. After the administration of glutaminic acid elimination of ammonia is further decreased and the quantity of uric acid crystals is increased. Loading with glutaminic acid may also cause an attack of renal pain in the individual suffering from this defect but the administration of ammonium chloride does not cause any increase in ammonia production. It seems probable that the enzymatic defect is connected with the presence of antigen $B$ in the erythrocytes and that it is inherited as a dominant autosomal feature. A suitable diet to make the urine alkaline allows kidneys to function efficiently in individuals suffering from this defect.

The formation of stones in the urinary tract is most frequently caused by an increase in the concentration of one or several components of urine. A change in the concentration of hydrogen ions in the urine may also be a significant factor, leading to reduced solubility of its components and to their precipitation in the urinary tract, even in cases when these components are eliminated by the kidneys in normal quantities (Melick and Henneman, 1958).

In certain cases of nephrolithiasis caused by uric acid stones, neither a raised uric acid level in the blood was observed nor an increase in the excretion of uric acid. There were no indications of metabolic acidosis. Even so, these individuals constantly excreted acid urine ( $p \mathrm{H} 4 \cdot 4$ to $5 \cdot 1$, mean value $4 \cdot 8$ ) and eliminated a smaller amount of ammonia than normal. Most of the individuals described by Henneman, Wallach, and Dempsey (1962) were 60 years old, and $50 \%$ of them were Italians or Jews. For these reasons the authors suggested that in the mechanism of the formation of uric acid stones in individuals without hyperuricaemia and hypericuria and no impairment of the acid-base equilibrium, a fundamental part may be played by an inborn Received for publication 24 April 1964. metabolic defect causing a decrease in the production of ammonia and excretion of a more acid urine. A decrease in solubility of uric acid in an acid environment leads to its precipitation in the urinary tract, and, frequently, to the formation of stones.

The suggestion of Henneman and his colleagues is to a certain extent confirmed by our own observations. In three generations of the same family, without regard to age or sex, we determined a decrease in elimination of ammonia by the kidneys, elimination of urine of a higher acidity than that shown by control individuals, and the presence of a relatively large quantity of crystals of uric acid in the urine sediment. All the individuals in whom these changes were determined are members of one family and have a dark skin, black eyes, and dark hair; in all of them the erythrocytes show the presence of antigen B. None of them showed any pathological symptoms and kidney function was normal. The purpose of our present paper is the elucidation of the mechanism leading to the changes as observed in the urine excreted, bearing in mind the possibility of the existence of a metabolic defect ultimately responsible for the precipitation of uric acid in the urinary tract. 


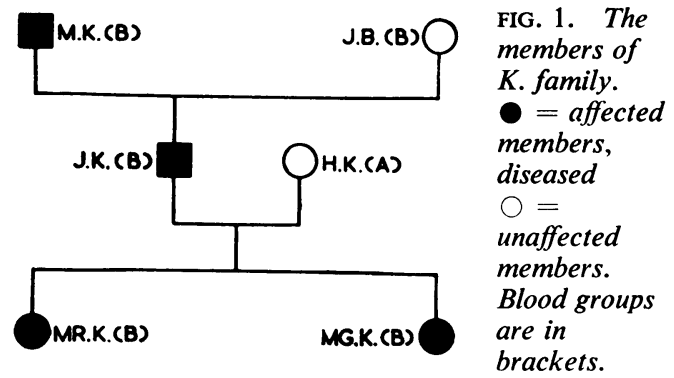

MATERIALS AND METHODS

The four members of the family studied were M.K., male, aged 78; J.K., aged 42, the son of M.K.; MR.K., aged 12, the daughter of J.K. and MG.K., aged 9, the other daughter of J.K. (Fig. 1). As a control, H.K., the mother of MR.K. and MG.K., was also examined. She represents a nordic type. Antigen A was determined in her erythrocytes. She shows no renal symptoms and no uric acid crystals were found in the urine.

The control group consisted of nine men and five women, aged 20 to 34 years, who were clinically well and without abnormal laboratory findings. In all persons belonging to this control group the daily ammonia excretion, $p \mathrm{H}$ of the fresh urine, as well as its titratable acidity, were determined. These examinations were performed twice, first without loading and then after loading with glutamic acid for six days in doses of $10 \mathrm{~g}$. per day. In five persons of the control group, these examinations were made three times, since for six days they were additionally loaded with ammonium chloride in daily doses of $4 \mathrm{~g}$. The interval between loading with glutamic acid and with ammonium chloride was three weeks. Of the family group examined, only J.K. underwent all the tests. With the remaining three, loading with ammonium chloride proved impossible, since even the first dose led to nausea and vomiting. With H.K. it was considered sufficient to determine the excretion of ammonia and the $p \mathrm{H}$ value of the urine and its titratable acidity without loading.

During the examination all the individuals ate their normal diet.

\section{RESULTS}

ELIMINATION OF AMMONIA In the members of the $\mathrm{K}$. family the amount of ammonia eliminated during 24 hours in the urine was by M.K. $19.0 \mathrm{mEq}$., J.K. $11 \cdot 0$ mEq., MR.K. 7.0 mEq., MG.K. 22 mEq., compared with the average elimination in a control group of $40.2 \mathrm{mEq}$. After loading with glutamic acid, these differences still grew in some of the persons investigated, whereas in others they remained practically unchanged (M.K. $17.0 \mathrm{mEq}$., J.K. $8.0 \mathrm{mEq}$., MR.K. 8.0 mEq., MG.K. 17.0 mEq.) compared with average values found in the control group of $35 \mathrm{mEq}$. (Fig. 2). After loading with ammonium

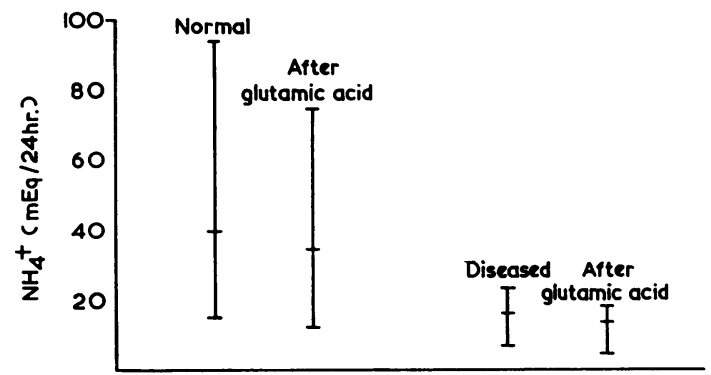

FIG. 2. The urinary excretion of ammonia in controls and patients before and after loading with glutamic acid.

chloride J.K. eliminated $7 \mathrm{mEq} . / 24 \mathrm{hr}$. of ammonia in the urine. The average values for the control group were $67 \mathrm{mEq} . / 24 \mathrm{hr}$.

TITRATABLE ACIDITY OF THE URINE In the members of the K. family the initial values, compared with the average of the control group ( $23.3 \mathrm{mEq} . / 24 \mathrm{hr}$.) were both lower (J.K. 14 mEq., M.K. $17 \mathrm{mEq}$.) and higher (M.K. $41.6 \mathrm{mEq}$, and MG.K. $40 \mathrm{mEq}$.). After loading with glutamic acid there was a distinct increase in titratable acidity of the urine in all of them (J.K. $32.2 \mathrm{mEq} . / 24 \mathrm{hr}$., M.K. $51.6 \mathrm{mEq} . / 24 \mathrm{hr}$., MG.K. $52 \mathrm{mEq} . / 24 \mathrm{hr}$, , and MR.K.20.1 mEq./24 hr.). The average value for the control group after loading with glutamic acid remained almost unchanged (24 mEq. $/ 24 \mathrm{hr}$.). In J.K. the titratable acidity after loading with ammonium chloride was $21 \mathrm{mEq} . / 24 \mathrm{hr}$. and in the control group $56.5 \mathrm{mEq}$./ $24 \mathrm{hr}$., on average.

COEFFICIENT $\mathrm{NH}_{3} / \mathrm{TA}^{1}$ In the various members of the $K$. family the values of this coefficient were much lower than in the control group and, as a rule, less than 1 (Fig. 3). They were further decreased after loading with glutamic acid (J.K. 0.79 and 0.25 , M.K. 0.46 and 0.31, MG.K. 0.55 and 0.33, MR.K. 0.41 and 0.44 ). For H.K., the coefficient was $1 \cdot 25$, thus in the normal range. After loading with ammonium chloride the value of the coefficient reached 0.33 , a value slightly higher than after loading with glutamic acid.

$p H$ VALUE OF URINE ${ }^{2}$ The initial $p H$ values of the urine of the members of family $\mathrm{K}$. were somewhat lower than the values of the control group, In the persons examined a slight decrease of the urinary $p \mathrm{H}$ was observed after loading with glutamic acid, in J.K. from $5 \cdot 5$ to $5 \cdot 3$, in M.K. from $5 \cdot 2$ to 4.9 , in MR.K. from $5 \cdot 3$ to $5 \cdot 2$, and in MG.K. from $5 \cdot 5$ to

${ }^{1}$ This is the ratio of $\mathrm{mEq}$. ammonia eliminated in the urine during 24 hours to the $\mathrm{mEq}$. acid also eliminated during 24 hours.

${ }^{2}$ Measured with fresh urine excreted in the early morning. 


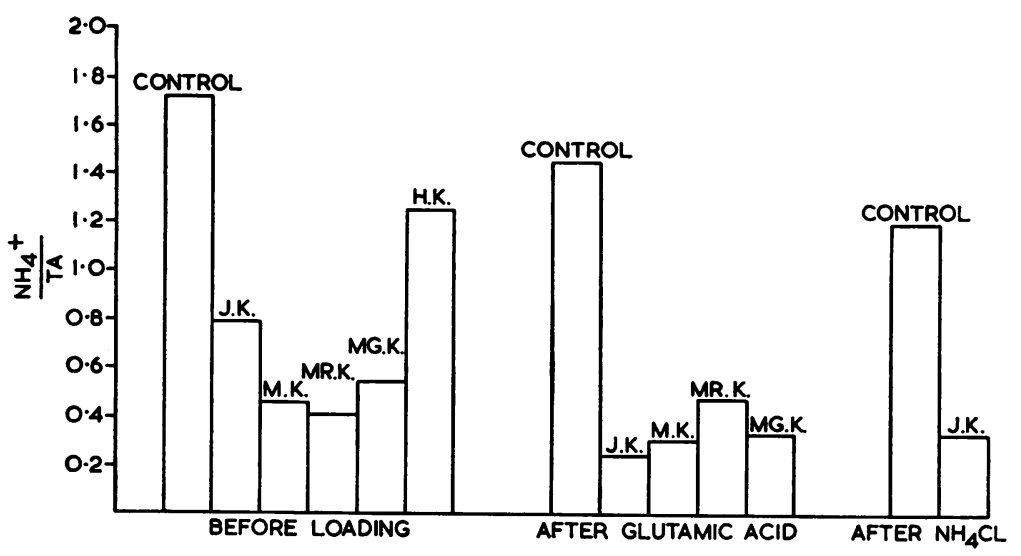

FIG. 3. The ratio of ammonia excretion and titratable acid in normals and in members of the $K$. family before and after loading with glutamic acid and ammonia chloride.

5.2. In J.K. the $p H$ value dropped a further $0 \cdot 3$ to $5 \cdot 2$, after loading with ammonium chloride.

\section{DISCUSSION}

The most important laboratory changes in the renal function of the members of the $K$. family are distinctly reduced elimination of ammonia, further decreased after loading with glutamic acid and ammonium chloride; excretion of urine with a reduced $p \mathrm{H}$ value, lowered further by the administration of glutamic acid and ammonium chloride; markedly reduced values for the coefficient $\mathrm{NH}_{3} / \mathrm{TA}$, reflecting reduced ammonia levels and an increase

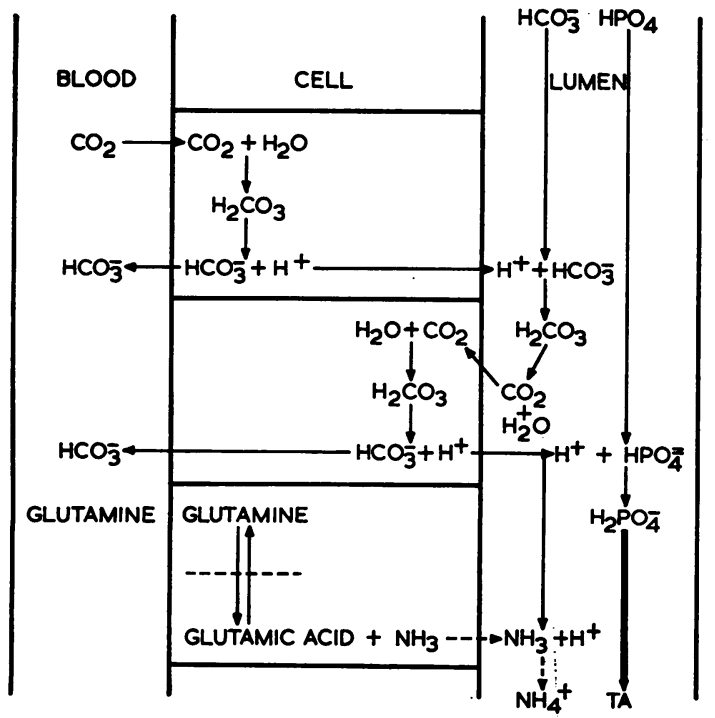

FIG. 4. The schema of renal excretion of hydrogen ions in the case of probable glutaminase defect. in titratable acidity in the urine; large quantities of uric acid crystals in the urinary sediment.

Clinical symptoms simultaneously observed worth mentioning were intermittent irritation of varying intensity of the lower part of the urinary tract; an attack of renal pain in J.K. after accidental loading with large doses of glutamic acid; hydronephrosis with nephrectomy in M.K.

The mechanism of the functional renal disturbances in the members of the $\mathrm{K}$. family as enumerated above, which were fully compensated, can be explained by assuming, according to Henneman et al. (1962), that in this family there was a genetic enzymatic defect which lowered the production of ammonia by the kidneys, in a quantity sufficient to bind the major part of the acid equivalents which reach the distal tubule from the proximal part of the nephron. The enzymatic defect postulated refers probably to the glutaminase which normally occurs in greater quantities in the cells of the distal tubules and is responsible for the production of the major part of the ammonia excreted in the urine (Fig. 4). This supposition is supported by the fact of the excretion of smaller quantities of ammonia in the urine, and its reduced elimination after loading with glutamic acid, even leading to an attack of renal pain in one subject; no increased ammonia elimination and a slight decrease of elimination established in J.K. after administration of ammonium chloride; the increase in titratable acidity of the urine in the majority of the members of the K. family, as well as their excreting urine of relatively low $p \mathrm{H}$ value.

Because the members of the $\mathrm{K}$. family who were examined are strikingly similar in appearance and are of the same blood group, and the changes in the urine appeared independently of sex and age, we may postulate that the enzymatic defect described is a genetic feature of dominant character, autosomally connected with the presence of antigen $B$ in the 
erythrocytes. This assumption is supported by the fact that in H.K., the mother of MR.K. and MG.K., the laboratory findings showed no abnormal results.

The frequency of the occurrence of stones consisting of uric acid was calculated to be $2.6 \%$ (Nicholas and Leifeste, 1958). It must be assumed that some of the individuals with that kind of nephrolithiasis suffer from the enzymatic defect described. To this group must be added all those persons in whom only urinary 'sand', consisting of uric acid crystals, is formed and generally are treated as completely healthy persons. Diagnosis of this type of defect, especially when only urinary sand is in evidence, would be of great practical significance since by suitable diet it would be possible to prevent nephrolithiasis, which often leads to nephrectomy. It is necessary, therefore, to establish the frequency of the occurrence of this type of enzymatic defect in the country's population. This study we intend to make the object of further investigation.

\section{REFERENCES}

Henneman, P. H., Wallach, S., and Dempsey, E. F. (1962). J. clin. Invest., 41, 537.

Melick, R. A., and Henneman, P. H. (1958). New Engl. J. Med., 259, 307.

Nicholas, H. O., and Leifeste, H. F. (1958). Clin. Chem., 4, 267. 